\title{
Beobachtungen der kleinen Planeten 1898 DV bis EA.
}

Die nachfolgenden mittleren Oerter sind aus photographischen Aufnahmen am Astrophys. Observatorium auf dem Königstuhl von $A$. Schwassmann und $W$. Villiger erhalten worden.

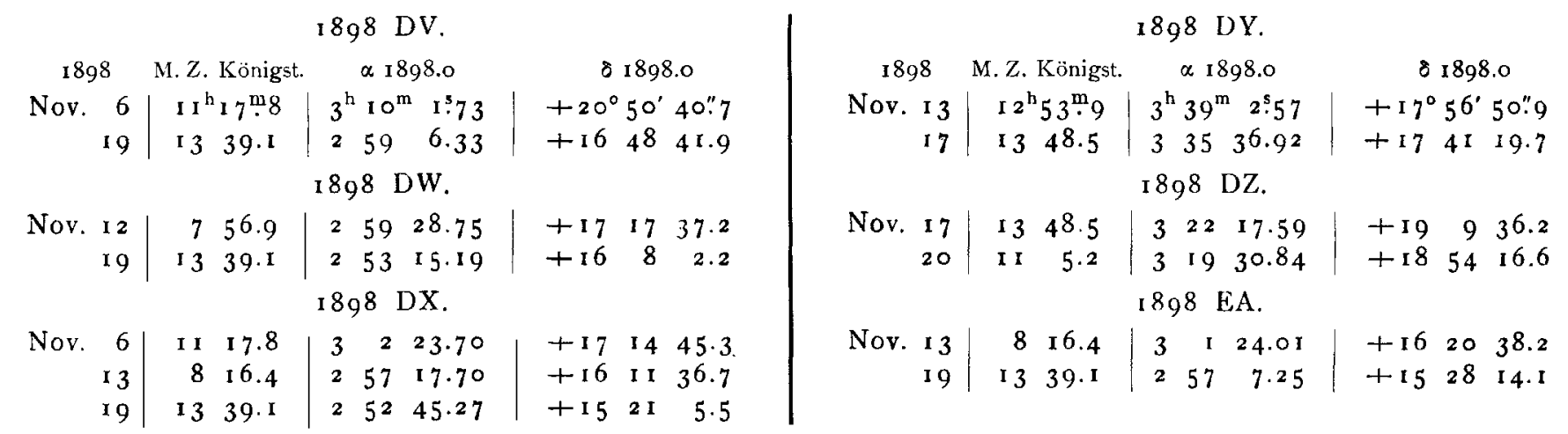

Die Positionen von Nov. 6 und 12 wurden durch Messung von Distanzen und graphische Auftragung derselben bestimmt, während die übrigen Oerter mit Hülfe des parallaktischen Messaparates des Observatoriums erhalten wurden.

Königstuhl, i 898 Nov. 30 .

M. Wolf.

Beobachtungen des Planeten 1898 ED.

\begin{tabular}{l|l|c|c|c|c|c|c|c|c|}
\hline $\mathrm{s} 898$ & M. Ortszeit & $\Delta \alpha$ & $\Delta \delta$ & Vgl. & Gr. & $\alpha$ app. & $\mid \log p . \Delta$ & $\delta$ app. & $\log p . \Delta \mid \operatorname{Red.ad} 1$. app. $\mid *$ \\
\hline
\end{tabular}

Auf der Sternwarte des Collegio Romano in Rom von Prof. E. Millosevich.

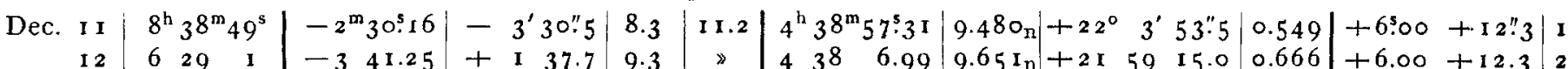

Auf der Sternwarte in Arcetri von Prof. A. Abetti.

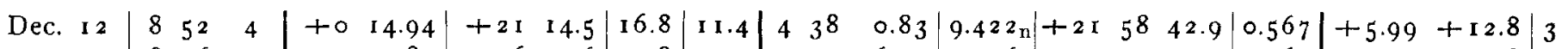

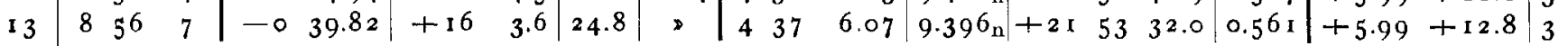

\begin{tabular}{|c|c|c|c|}
\hline & $\begin{array}{l}\text { Mittlere } \\
\alpha \text { i } 898.0\end{array}$ & $\begin{array}{r}\text { Oerter der } \\
\text { o I } 898.0\end{array}$ & it \\
\hline & $4^{h} 4 I^{m} 21^{s} \cdot 47$ & $+22^{\circ} \quad \gamma^{\prime}$ II". 7 & $\mathrm{AG}$. \\
\hline & $4 \quad 41 \quad 42.24$ & +215725.0 & B. 1526 \\
\hline & $\begin{array}{lll}4 & 37 & 39\end{array}$ & +2137 I 5.6 & $B B . V I+2 I: 69 I$ \\
\hline
\end{tabular}

\section{Schreiben von Prof. E. Millosevich an den Herausgeber.}

La prego di annunziare nelle A. N. che, avendo impreso il calcolo degli elementi ellittici più probabili del pianeta (433) (1898 DQ), pregherei gli astronomi, che possezzono osservazioni o che ne facessero nell' avvenire, di voler solleci. tamente pubblicarle.

E. Millosevich.

Pianeta (283) Emma. Corr. dell' effem. (Veröff. R. I. Nr. 7): Dic. $16-5^{5}$ o:o. Gr. 1 r.9. E. Millosevich.

Pianeta (377) (1893 AN). Corr. dell' effem. (Veröf. R. I. Nr. 7): Dic. $9-\mathbf{r}^{\mathrm{m}} 28^{\mathrm{s}}+2: 2$. Gr. 1 1.6. E. Millosevich.

Notiz. Formulare zum Eintragen von Cometen- und Planetenbeobachtungen können jederzeit von der Expedition dieser Zeitschrift, Kiel Niemannsweg ı०3, bezogen werden. 